\title{
Ensino de história da américa e a formação de uma identidade histórica
}

DOI: 10.46814/lajdv3n3-022

Recebimento dos originais: 23/12/2020

Aceitação para publicação: 26/02/2021

\author{
Gerson Luiz Buczenko \\ Doutor em Educação \\ Centro Universitário Internacional Uninter \\ Rua 13 de maio, 538. Centro. Curitiba/PR \\ CEP 80.510-030 \\ E-mail: buczenko@uol.com.br
}

\section{RESUMO}

Este artigo pretende expor algumas ideias sobre o ensino de História da América e a formação de uma identidade histórica, baseando-se principalmente na experiência em sala de aula, com turmas do ensino médio e superior. A pergunta motivadora da pesquisa foi assim colocada: Com o ensino de história da América é possível obter a formação de uma identidade histórica? Como objetivo geral do presente tema pretende-se analisar a formação de uma identidade histórica por meio das percepções sobre o ensino de História da América. Os objetivos específicos foram assim definidos: conhecer os posicionamentos teóricos de autores que discutem o ensino de História da América; analisar os conceitos de identidade e identidade histórica; e, avaliar a presença da História da América, em livros didáticos do ensino médio.

Palavras - chave: História, Ensino, História da América, Identidade histórica.

\begin{abstract}
This paper aims to present some ideas about teaching history of America and the formation of a historical identity, based mainly on experience in the classroom with groups of high school and college. The driving research question was well placed: With the teaching of American history is possible to obtain the formation of a historical identity? As a general objective of this theme is intended to analyze the formation of a historical identity through the perceptions about teaching American History. The specific objectives were defined as follows: knowing the theoretical positions of the authors discussing the teaching of American History; analyze the concepts of identity and historical identity, and to evaluate the presence of American History in high school textbooks.
\end{abstract}

Keywords: History, Education, History of America, Historical identity.

\section{INTRODUÇÃO}

A História da América se faz presente nos livros didáticos da atualidade relatada de forma indireta, ora em capítulos dispostos que oportunizam uma abordagem particular da América, ora com informações que além de atuais, possibilitam análises críticas sobre os contextos sócio-políticos sem uma contextualização sobre possíveis laços identitários entre os países que compõem o continente Americano. 
Esse contexto, aliado ao acesso e velocidade das informações, que também estão disponíveis sobre os países vizinhos para o Brasil, permite ao professor de História uma maior valorização de aspectos inerentes à formação de nossa História regional. Havendo essa intencionalidade por parte do docente em abordar a História da América, com temas ou capítulos dispostos no livro didático ou através de textos de apoio, no sentido de dar uma unidade ao ensino da História da América, pode-se despertar o interesse em refletir sobre os laços de uma identidade histórica americana ou latinoamericana em nossos alunos.

A identidade é uma das correntes trilhadas pela História Cultural, uma construção simbólica de sentido que organiza um sistema compreensivo a partir da idéia de representação segundo Pesavento (2008, p. 89). Se há identidade, é porque houve uma construção de memórias, fatos e representações, que tendem a perenizar uma identidade.

Nossa indagação de pesquisa está assim colocada: com o ensino de história da América é possível obter a formação de uma identidade histórica? Como objetivo geral do presente tema, pretende-se analisar a formação de uma identidade histórica por meio das percepções sobre o ensino de História da América. Como objetivos específicos, para atender ao objetivo geral colocado, definiram-se: conhecer os posicionamentos teóricos de autores que discutem o ensino de História da América; analisar os conceitos de identidade e identidade histórica; e, avaliar a presença da História da América, em livros didáticos do ensino médio.

O presente projeto foi desencadeado através de uma pesquisa de caráter exploratória, com a coleta de dados por meio de uma pesquisa bibliográfica e documental, buscando-se matrizes teóricas sobre o ensino de História da América e a identidade histórica.

Temos ainda, como fio condutor o estruturismo metodológico, que segundo Lloyd (1995, p. 220) tenta articular os níveis micro e macro da análise social, sem subordiná-los mutuamente, explicando como a personalidade, as intenções e as ações humanas interagem com a cultura e a estrutura para determinar um ao outro e as transformações sociais ao longo do tempo. Para análise das percepções de identidade, diante dos dados coletados e examinados, buscamos apoio de Pesavento (2008), Prado (2011) e Rüsen $(2001 ; 2010)$ entre outros autores pesquisados.

\section{O ENSINO DE HISTÓRIA DA AMÉRICA}

No ensino de História da América, diante de novas tecnologias disponíveis e livros didáticos produzidos com uma riqueza de informações, como imagens, documentos e várias sugestões de leituras e filmes, além do assessoramento pedagógico ao professor, a História tenta tornar-se atrativa para o aluno, uma vez que possibilita o contato com realidades históricas muito diferentes, porém, muito próximas como é o caso dos países fronteiriços ao Brasil. 
Conectar nossa realidade com um país vizinho, possibilitando comparações de caráter histórico, com reflexões sobre a atualidade, traz uma maior compreensão do processo histórico ao qual fomos e ainda somos submetidos, por habitarmos o mesmo continente.

Ao lecionar História para o ensino médio e superior, percebe-se certa desvalorização daquilo que faz parte da História do continente, de nossa história regional. Valoriza-se por outro lado, aspectos de uma História em formato tradicional que se pretende geral, fundamental também para o conhecimento do aluno; porém, que não se enfatiza nossa História regional, prejudicando as análises e correlações que possam ocorrer com fatos históricos que se relacionam diretamente com a História do Brasil e, por conseguinte em prejuízo do aluno.

No ensino da História da América as relações com a História então conhecida como geral, proporcionam uma grande oportunidade para buscar-se o avanço em novos conhecimentos, onde a ação de personagens históricos conhecidos, mais próximos, de nosso continente, foram influenciadas por contextos históricos maiores, momentos que oportunizam um aprofundamento do conhecimento histórico, novas conexões e reflexões, para o professor e principalmente para o aluno.

A História da América na atualidade, em função das condições socioeconômicas e especialmente políticas, vividas não só pelo Brasil, mas em especial pelos países vizinhos, merece uma atenção especial por parte dos professores e de seus alunos. São novos contextos onde a América Latina chama a atenção do restante dos países do globo, principalmente pela tentativa de unidade através do MERCOSUL, e dessa unidade pretendida, podemos buscar uma identidade para a América, não só territorial, mas também histórica e cultural.

No âmbito acadêmico, com o entrosamento das universidades e participação assídua de pesquisadores, as fronteiras são somente geográficas, caminhando para uma articulação e troca de conhecimento constante, valorizando-se o conhecimento que é produzido e difundido a partir da visão da América Latina.

Estudar e lecionar sobre a História da América apresenta-se hoje como um grande desafio para professores e alunos da educação brasileira. Começando pelo formato dado aos vestibulares que entre tantos conteúdos importantes a serem cobrados nas provas, no que se refere à história da América, permanecem com uma cobrança de forma factual, priorizando-se alguns fatos históricos geralmente conectados à própria História do Brasil ou a personagens de renome na História da América.

Pela influência francesa e norte-americana em nossa educação, o idioma espanhol foi culturalmente preterido em nossa formação básica, sendo também um entrave para uma aproximação de várias culturas das quais somos vizinhos, onde então fomos direcionados a olhar para a Europa e USA, como credores de nossa existência e formação. 
Interessante observar que o MERCOSUL incentivou o ensino de espanhol, mas não patrocinou a disciplina da História do continente. Além disso, o Brasil parece ter se descolado dos demais países da América latina, pois agora o brasileiro médio tende a pensar que o Brasil, diferentemente dos demais países latino-americanos, deu muitos passos à frente em termos de crescimento econômico e pode servir de modelo aos demais. (PRADO, 2011, p. 11).

A História da América foi preterida como disciplina já no Colégio Pedro II (OLIVEIRA, 2006, p. 1), uma vez que em 1838 a disciplina de História foi introduzida em caráter obrigatório; porém, uma história voltada para um modelo de civilização francesa ou européia, com tempos e espaços sociais da Europa divididos cronologicamente em história antiga, medieval, moderna e contemporânea, formato à época ideal para se compreender a História universal.

\begin{abstract}
Primeiramente, a História da América era desprestigiada nos currículos escolares em razão das divergências político-ideológicas entre o Brasil e os demais países latino-americanos, sobretudo os do Cone Sul (Uruguai, Argentina e Paraguai). A adoção pelo regime político monárquico foi o elemento mais emblemático no distanciamento do Brasil com os demais países latino-americanos, o que resultou na não identificação do Brasil enquanto um país americano. (OLIVEIRA, 2006, p. 1).
\end{abstract}

A História da América surgiria na educação brasileira a partir da Reforma Educacional de Fancisco Campos, em 1931, onde História do Brasil e História Universal, passariam a ser englobadas pela disciplina de História da Civilização, incluindo-se assim de forma abrangente conteúdos sobre a História da América, sendo o núcleo principal da disciplina a História do Brasil (OLIVEIRA, 2006, p.2). A Reforma Educacional de Capanema em 1942 vem a fortalecer a necessidade de construir valores nacionalistas, sendo o ensino da História do Brasil seu principal instrumento, assim, perdendo espaço o ensino da História da América (DIAS, 1999, p.44).

No final da década de 1940, o Colégio Pedro II, coloca em prática uma nova seriação, criando a cadeira de História da América para a segunda série do curso ginasial, sob a égide do professor catedrático João Batista de Mello e Souza, segundo Dias (1999, p. 4). E, em 1951, através da Lei 1359 e Portaria $n^{\circ} 724$, do Ministério da Educação, estabelece-se a disciplina de História da América, em caráter obrigatório para a segunda série do curso ginasial de todas as escolas de ensino secundário do país, contemplando quase exclusivamente conteúdos de História da América, sendo apenas duas das dez unidades dedicadas ao Brasil (SILVA, 2004, p. 91). Este ato veio a impulsionar também o mercado editorial, que até então praticamente nada produzia sobre o tema.

Vivia-se, além disso, a era do pan-americanismo, um projeto político que apregoava a unidade do continente em nome da preservação dos seus valores. Tratava-se, na verdade, de uma estratégia imperialista norte-americana, no bojo dos conflitos da guerra fria, de modo a assegurar seu domínio sobre todo o continente, eliminando ou esterilizando qualquer ameaça comunista. (SILVA, 2004, p. 92). 
A partir de 1960, após intensos debates é implantada em alguns estados do Brasil (Minas Gerais e São Paulo) a disciplina de Estudos Sociais que com a Reforma Educacional imposta pela Lei 5692 de 1971, vem a sacramentar a implantação dessa disciplina em todo o país, assim como Educação Moral e Cívica e Organização Social. História e Geografia foram mantidas com carga horária muito reduzida, para abrir espaço para o ensino profissionalizante, uma tônica durante o regime militar.

\begin{abstract}
A recomendação de estudos de história da América sem hostilidades, livres de conceitos ofensivos, sem ódios, valorizando o estudo da cultura e do desenvolvimento fazia-se presente no ensino médio. O propósito era valorizar a hegemonia americana na América e no mundo, e a paz entre as nações americanas e a identificação entre elas são exemplos de temas de estudos sugeridos. Ao adotar essa concepção, o ensino de história assumia a tarefa de formação cívica, impondo regras de conduta política por meio do estudo de temas e conceitos que eram de interesse central do governo. (GUIMARÃES, 2011, p.24).
\end{abstract}

Em 1978, segundo Silva (2004, p. 95) no Estado de São Paulo passou a figurar no currículo do $2^{\circ}$ Grau, $1^{a}$ Série, o ensino sobre a História do continente americano, com muita liberdade de abordagens sobre o conteúdo, fato que repercutiu de imediato na produção bibliográfica uma vez que o mercado se ressentia de obras que explorassem a História da América em maior detalhe.

Com o ímpeto paulista, seguido por outros estados, o ensino de História da América permaneceu apesar de todos os contextos políticos existentes à época. Assim, com maior autonomia para as escolas a partir de 1990, reforçada pela formulação dos Parâmetros Curriculares Nacionais, o ensino de História da América persiste em várias instituições de ensino básico e superior, embora pouco aprofundado, para alunos do ensino médio e superior em História (licenciaturas e bacharelados).

O latino-americano, em especial o brasileiro, parece negar suas origens, conta e seleciona o lado bom da história para se identificar com ela. A origem negra é negada; a indígena vista como covarde e a asiática deixada de lado. (FERNADES; MORAIS, 2008, p. 160).

\title{
3 IDENTIDADE E IDENTIDADE HISTÓRICA
}

Ao abordarmos no Ensino de História os conceitos de identidade e identidade histórica, vamos buscar estes conteúdos em três momentos, destacando a construção da identidade como produção social, em seguida a identidade como produção cultural e por último, a identidade histórica na visão de Jörn Rüsen.

Inicialmente vamos abordar o conceito de identidade como produção social, que segundo Silva (2011b, p. 96) ao trabalhar os conceitos de identidade e diferença pontua que a identidade

não é uma essência; não é um dado ou um fato - seja da natureza, seja da cultura. A identidade não é fixa, estável, coerente, unificada, permanente. A identidade tampouco é homogênea, definitiva, acabada, idêntica, transcendental. Por outro lado, podemos dizer que a identidade é uma construção, um efeito, um processo de produção, uma relação, um ato performativo. A identidade é instável, contraditória, fragmentada, inconsistente, inacabada. A identidade está 
ligada as estruturas discursivas e narrativas. A identidade está ligada a sistemas de representação. A identidade tem estreitas conexões com relações de poder.

Alinhado a este pensamento, destacando nas palavras de Silva (2011b), caminhamos para algo que está inserido na prática social, ou ainda, como produção social, assim, a identidade é marcadamente temporal, ou seja, reflete um momento vivido de um determinado grupo social, sujeito a questões socioeconômicas particulares, que vão influenciar o aspecto identitário social e por consequiência pessoal.

Woodward (2011, p. 39) afirma que "as identidades são produzidas em momentos particulares no tempo", assim, esta particularidade no tempo pode ser definida como histórica, uma vez que está inserida no contexto de temporalidade e, de um momento de produção social específico que tem uma identidade particular.

A identidade se fortalece também, à medida que o indivíduo se coloca na história, como partícipe do processo histórico, sendo este processo reforçado pelo processo social (educativo, econômico, familiar) imposto pela força de um discurso presente na sociedade da qual faz parte. Assim, para Hall (2011, p. 109),

é precisamente porque as identidades são construídas dentro e não fora do discurso que nós
precisamos compreendê-las como produzidas em locais históricos e institucionais específicos,
no interior de formações e práticas discursivas específicas, por estratégias e iniciativas
específicas. Além disso, elas emergem no interior do jogo de modalidades específicas de poder
e são, assim, mais o produto da marcação da diferença e da exclusão do que o signo de uma
unidade idêntica, naturalmente constituída, de uma 'identidade' em seu significado tradicional
- isto é, uma mesmicidade que tudo inclui, uma identidade sem costuras, inteiriça, sem
diferenciação interna.

O conceito de identidade como produção cultural tem por base o pensamento de Peter Burke (2008) e, segundo o mesmo, o termo culture, ou Kultur, foi empregado com freqüência na Alemanha e na Inglaterra no século XIX. Essa valorização da cultura englobando a história e a história cultural pode ser dividida em quatro fases, ainda segundo Burke (2008): a fase clássica de 1800 a 1950; da história social da arte que começou em 1930; a descoberta da história da cultura popular, na década de 1960; e a nova história cultural.

Burke (2008) relata que este termo já se referiu às artes e à ciência, em seguida passou a representar às manifestações equivalentes no âmbito popular, como a música folclórica, a medicina popular entre outros saberes praticados pela população. $\mathrm{Na}$ contemporaneidade a palavra cultura passou a referenciar uma vasta significação, como imagens, ferramentas, casas, entre outros e, práticas sociais como conversar, ler e jogar. 
Com a aproximação da cultura, o interesse por pesquisadores de outras ciências, como a Antropologia, por exemplo, bem como, de historiadores, ampliou-se ainda mais se tornando mais visível o interesse pela cultura, história cultural e estudos culturais a partir das décadas de 1980 e 1990. Nesse sentido são referências os trabalhos do antropólogo Clifford Geertz (1989), assim como historiadores culturais do final do século XX, como Emmanuel Le Roy Ladurie na França, Lynn Hunt nos Estados Unidos, Carlo Ginzburg na Itália e, Hans Medick na Alemanha, segundo Peter Burke.

Assim, podemos observar que a preocupação com identidade é um contexto que vem sempre à tona, em função dos movimentos sociais na História da Humanidade e, quando a cultura surge no cenário contemporâneo, valorizada principalmente ao focar o aspecto popular em sua generalidade, temos uma abordagem diferenciada também pela chamada nova história cultural no que se refere à identidade.

A preocupação com a construção da identidade é uma característica importante da NHC, o que não é de surpreender, numa época em que a política de identidade se tornou questão de grande relevância em muitos países. Há um interesse cada vez maior em documentos pessoais ou, como dizem os holandeses, 'documentos ego'. (BURKE, 2008, p. 116).

Lynn Hunt (1992), ao destacar a história da história cultural e as várias possibilidades que intelectuais como Roger Chartier, por exemplo, vêem na aproximação com a cultura, afirma que "quanto mais culturais se tornarem os estudos históricos, e quanto mais históricos se tornarem os estudos culturais, tanto melhor para ambos." (p. 29). Assim, a identidade segundo Burke (2008, p. 128), "é continuamente reconstruída ou negociada."

Pesavento (2008, p. 69) ao dedicar um capítulo em sua obra denominado, "correntes, campos temáticos e fontes: uma aventura na história”, dá um destaque especial para as identidades, posicionando este conceito como um campo de pesquisa para a História Cultural.

Enquanto representação social, a identidade é uma construção de sentido, que organiza um sistema compreensivo a partir da idéia de pertencimento. A identidade é uma construção imaginária que produz a coesão social, permitindo a identificação da parte com o todo, do indivíduo frente a uma coletividade, e estabelece a diferença. A identidade é relacional, pois ela se constitui a partir de uma identificação de alteridade. Frente ao eu ou ao nós do pertencimento se coloca a estrangeiridade do outro. (PESAVENTO, 2008, p. 90).

A construção de sentido, o pertencimento, a coesão social, a coletividade, e alteridade, são elos fundamentais para a consciência histórica ${ }^{1}$, possibilitando a orientação ao aluno diante das temporalidades que lhe são apresentadas. Segundo ainda Pesavento (2008, p. 90), para a construção de uma identidade, que cria também o sentimento de pertencimento a um dado grupo, esta se dá na

\footnotetext{
${ }^{1}$ A consciência histórica é a consciência humana que fornece sentido temporal à vida, pois relaciona num continuum temporal o passado, presente e futuro. (GERMINARI, 2010, p. 17).
} 
"confrontação com o outro", um reconhecimento que pode estar em proximidade com o real ou não. Outro destaque na visão de Pesavento (2008, p. 91) é a defesa de que a identidade "se constrói em torno de elementos de positividade", fator fundamental para que ocorra a união entorno de atributos reconhecidos e valorizados socialmente.

\begin{abstract}
Assumir uma identidade implica encontrar gratificação com esse endosso. A identidade deve apresentar um capital simbólico de valoração positiva, deve atrair a adesão, ir ao encontro das necessidades mais intrínsecas do ser humano de adaptar-se e ser reconhecido socialmente. Mais do que isso, a identidade responde, também, a uma necessidade de acreditar em algo positivo e a de que possa se considerar como pertencente. Enquanto construção imaginária de sentido, as identidades fornecem como que uma compensação simbólica a perdas reais da vida. Identidades gloriosas confortam e suprem carências na vida social e material, por exemplo. (PESAVENTO, 2008, p. 91-92).
\end{abstract}

$\mathrm{Na}$ análise de Carretero (2010), a identidade que advém da história escolar, é legitimadora de ações, buscando despertar o sentimento de pertencimento aos ideais de um grupo ou sociedade, afetada pelas novas relações de um mundo midiatizado, interligado e por consequiência, globalizado.

O conceito de globalização, então tem velhas significações, algumas das quais se referem a problemas que hoje retornam como o da identidade relacional e o encontro com os outros, $\mathrm{o}$ que marca tanto uma expansão quanto uma contração do mundo. Com efeito, os limites e fronteiras se abrem para o exterior e, por sua vez, fortalecem o interior e a identidade original como quando o 'Velho Mundo' se estendeu além da costa atlântica, do primeiro fuso do nacionalismo segundo Gellner $(1983)^{2}$, o qual olhava em direção à América, ao longo do qual sobreviria com maior violência o processo de culminou com a formação dos Estados nacionais. (CARRETERO, 2010, p. 140).

Uma realidade onde a identidade "original" é valorizada com o sentido de legitimar realidades que convivem com a ruptura e continuidade, imputam, assim, ao ensino da História um papel fundamental no sentido de levar o aluno à uma contextualização de sua História mais próxima.

Agora buscamos uma abordagem da identidade histórica tendo por base o pensamento de Rüsen (2001, p. 125), que assim define o processo de consolidação de identidades:

consolidar identidades mediante consciência histórica significa aumentar a acumulação de experiências significativas das mudanças do homem e de seu mundo, no tempo, com as quais e pelas quais os sujeitos humanos (na prática das relações sociais com os demais) exprimem quem são e o que pensam ser os outros. De acordo com campo da experiência histórica que venha a ser tido como significativo para o presente e que possa influenciar a formação da identidade histórica, mede-se também o horizonte temporal em que os agentes podem situar seu respectivo 'eu', no longo prazo, em meio às mudanças do mundo e de si mesmos.

Segundo Germinari (2010, p. 17), com base em Rüsen (2001), a consciência histórica é a competência interna de orientar a vida prática, fornecendo à vida um sentido temporal de continuidade

${ }^{2}$ GELLNER, Ernest. Nations and nationalism. Oxford: Blackwell, 1983. 
entre passado, presente e, o futuro. Assim, para Rüsen (2001, p. 126), a consolidação da identidade também:

consiste na ampliação do horizonte nas experiências do tempo e nas intenções acerca do tempo, no qual os sujeitos agentes se asseguram da permanência de si mesmos na evolução do tempo. O ponto extremo dessa consolidação de identidade é a 'humanidade', como supra-sumo dos pontos comuns em sociedade, com respeito à qual diversos sujeitos agentes, no processo de determinação de suas próprias identidades, determinam as dos outros de forma tal que estes se reconhecem nelas.

Ao estabelecer conexões entre o passado e o presente e, possibilitando uma perspectiva de futuro a identidade histórica auxilia no reconhecimento daquilo que é comum aos indivíduos, no momento em particular vivido pelo grupo, despertando o sentimento de pertencimento daquilo que há de comum seja do passado, seja no presente, realçando o caráter de temporalidade, fundamental para o aluno.

\begin{abstract}
A apropriação da história 'objetiva' pelo aprendizado histórico é, pois, uma flexibilização (narrativa) das condições temporais das circunstâncias presentes da vida. Seu ponto de partida são as histórias que integram culturalmente a própria realidade social dessas circunstâncias. O sujeito não se constituiria somente se aprendesse a história objetiva. Ele nem precisa disso, pois já está constituído nela previamente (concretamente: todo sujeito nasce na história e cresce nela). O que precisa é assenhorear-se de si a partir dela. Ele necessita, por uma apropriação mais ou menos consciente dessa história, construir sua subjetividade e torná-la a forma de sua identidade histórica. Em outras palavras: precisa aprendê-la, ou seja, aprender a si mesmo. (RÜSEN, 2010, p. 107).
\end{abstract}

Este processo de construção da identidade histórica não é pacífico, posto que o indivíduo esteja inserido em ambiente social (familiar, escolar, econômico) que tende a influenciar diretamente esta percepção de identidade histórica. Ao tomar consciência de sua história, assim como, ao perceber nas narrativas históricas, uma proximidade, um pertencimento à história, torna-se possível sentir-se inserido em uma história, fazendo parte de todo um contexto de vida que tem um sentido histórico, que possibilita uma conexão entre o passado e o presente, porém, sem perder a noção de si mesmo, reforçando o processo identitário.

\title{
4 HISTÓRIA DA AMÉRICA E LIVROS DIDÁTICOS
}

Ao analisar a História da América disposta nos livros didáticos, tendo aqui tomados como exemplo as obras: Nova História Crítica de Mario Schmidt, volume único, (2008) - PNLEM 20092011, e História Geral e do Brasil cujos autores são Cláudio Vicentino e Gianpaolo Dorigo, três volumes, (2010) - PNLEM 2012-2014, de imediato verificamos que a História da América está distribuída em alguns capítulos de ambas as obras. 
Para esta análise vamos adotar a palavra "América", como referência no sentido de localizar nos capítulos dos livros didáticos, conteúdos que remetem à História da América. Na obra, Nova História Crítica, verificamos que em função de ser um volume único, com conteúdo para os três anos do ensino médio, a “América” surge nos capítulos 12 - América contra a Europa; 16 - Colonização das Américas; 29 - Independências na América Espanhola; 37- Américas no Século XIX; e, 55 - América Latina no século XX. É importante destacar que é destinado um capítulo (24) para a Independência do EUA e vários para a História do Brasil como um todo.

Já na obra, História Geral e do Brasil, verificamos que no primeiro volume, que corresponde ao primeiro ano do ensino médio, a "América" não aparece em nenhum dos capítulos. No segundo volume, elaborado para o segundo ano, verificamos que a "América”, surge no capítulo 2 - A colônia portuguesa na América; 7 - América portuguesa: expansão e diversidade econômica; 8 - América espanhola e América Inglesa; e, 14 - As independências na América espanhola. No terceiro volume, destinado ao terceiro ano do ensino médio, a "América", não está presente nos capítulos do livro didático; porém, no capítulo 10 - Descolonização e lutas sociais no "Terceiro Mundo", com foco especial para os países da África e Ásia, é destinado um subtítulo "A América Latina e as Lutas sociais", apresentando os reflexos da guerra fria nos países da América Latina, abordando ainda a “América Central” e por último a "América Latina no século XXI”, com um total de dezoito páginas.

Assim, nos livros didáticos analisados, temos de forma efetiva a abordagem de conteúdos referentes à História da América, cabendo então ao professor de História o trabalho com tais conteúdos, no sentido de abordá-los com profundidade, podendo oportunizar ainda textos complementares e pesquisas sobre a História da América, com temas diversificados que podem ter como foco desde a pré-história da América, às características culturais particulares de cada país.

Uma riqueza de informações que podem possibilitar principalmente a consciência histórica que traz toda a temporalidade exposta e vivida no continente americano, colocando também a possibilidade dos aspectos identitários, fundamentais para a valorização de nossa História.

\section{CONCLUSÃO}

Se há identidade, é porque houve uma construção de memórias, fatos e representações, que tendem a perenizar uma identidade, assim, o ensino de História e em especial o ensino de História da América pode proporcionar esta grande oportunidade de conhecer a História do continente visto então, como um todo. Este ensino, influenciado pela visão européia por questões da própria colonização que deixou um grande peso étnico, cultural e político, por outro lado, proporcionou a condição de busca pela emancipação, liberdade e unidade, embora esta não tenha sido fortalecida por questões individualizadas dos países que compõem nosso grande continente. Com o fortalecimento desta visão 
da América possibilita-se a busca de memórias coletivas, fatos e representações de ideais maiores que estimulem uma identidade, principalmente no estudante brasileiro.

Em cena, então, o papel do professor uma vez que percebemos que a História da América está esparsa nos livros didáticos, não com a ênfase de valorizar a História do continente, mas de forma compartimentada, dividida em capítulos que se seguidos em ordem cronológica, podem deixar a idéia de uma História sem sentido para o aluno. Ao professor cumpre o papel de agente cuja intencionalidade e ações podem despertar a interação com a História e a cultura dos países que estão no mesmo continente, uma vez que nossa História está intimamente ligada à própria História das demais nações e as transformações sociais que, ao longo do tempo, ocorreram e que afetaram a todos, de forma diferenciada em cada nação em razão de suas especificidades culturais, políticas e econômicas.

Na visão de Rüsen (2010b, p. 97), no ensino de História é de fundamental importância a narrativa histórica ${ }^{3}$, principalmente em função de suas qualidades: de estar ligada ao ambiente da memória do próprio professor e de seus alunos; de organizar a unidade interna das dimensões do tempo, passado, presente e futuro por meio de um conceito de continuidade; e ainda, de estabelecer a identidade de seus autores e ouvintes. Esta narrativa está inserida em sala de aula, com uma potencialidade para despertar o interesse dos alunos não só pela História em geral, mas também pelo reconhecimento de si mesmo e de sua identidade enquanto jovem pertencente a um espaço geográfico com um contexto histórico do qual faz parte.

Prado (1994, p. 1), ao defender o interesse em estudarmos a História da América afirma que a América Latina tem que ser pensada, politicamente, como parte do mundo na qual o Brasil está inserido e cujos países vivem processos econômicos e políticos próximos e muitas vezes simultâneos. Assim, ao estimular e possibilitar as conexões entre os conteúdos de História da América pode-se não somente oportunizar ao aluno um maior conhecimento sobre a História do continente, mas despertar também laços identitários, hoje cada vez mais aparentes, que podem e devem unir os jovens da América Latina, vislumbrando um futuro sem preconceito e discriminação entre nações.

O ensino de História da América, ao buscar a valorização da história de suas nações, conectando-as em função dos laços do passado e presente, fortalecendo-os em função das necessidades que lhes são comuns, possibilita também uma perspectiva de futuro, talvez mais esclarecido das explorações e espoliações que ocorreram no passado, das lutas pela descolonização que ainda não cessaram e pelo reconhecimento de sua identidade individual, que uma vez somadas, podem

\footnotetext{
${ }^{3}$ Narrativa histórica: é um sistema de operações mentais que define o campo da consciência história. (RÜSEN, 2010b, p.95).
} 
proporcionar uma identidade do coletivo e principalmente, uma visão positiva das nações latinoamericanas. 


\section{REFERÊNCIAS}

BURKE, Peter. O que é história cultural? 2. ed. rev. ampl. Rio de Janeiro: Zahar, 2008.

CARRETERO, Mário. Documentos de identidade: a construção da memória histórica em um mundo globalizado. Porto Alegre: Artmed, 2010.

DIAS, Maria de Fátima Sabino. A História da América na cultura escolar no Brasil: identidade e utopia. Disponível em:

<http://www.periodicos.ufsc.br/index. php/perspectiva/article/view/11192/10669 > . Acesso em 01 abr. 2012.

FERNANDES, Luiz Estevam; MORAIS, Marcus Vinicius. Renovação da História da América. In: KARNAL, Leandro (org.). História na sala de aula: conceitos, práticas e processos. 5. ed. $1^{\text {a }}$. reimp. São Paulo: Contexto, 2008.

GERMINARI, Geyso Dongley. A história da cidade, consciência histórica e identidades de jovens escolarizados. 2010. 186 f. Tese (Doutorado em Educação) - Universidade Federal do Paraná, Curitiba, 2010.2 Disponível em: <http://dspace.c3sl.ufpr.br:8080/dspace/bitstream/handle/1884/24209/Texto1.pdf?sequence=1>. Acesso em: 13 nov. 2010.

HALL, Stuart. Quem precisa de identidade? In: SILVA, Tomaz Tadeu (Org.). Identidade e diferença: a perspectiva dos estudos culturais. 10. ed. Rio de Janeiro: Vozes, 2011. p. 103-133.

HUNT, Lynn. A nova história cultural. São Paulo: Martins Fontes, 1992.

LLOYD, Christopher. As estruturas da História. Rio de Janeiro: Zahar, 1995.

OLIVEIRA, Thalita Maria Cristina Rosa. O ensino de história da América como instrumento de construção da identidade nacional (1930-1950). Disponível em: <http://www.rj.anpuh.org/resources/rj/Anais/2006/ic/Thalita\%20Maria\%20Cristina\%20Rosa\%20Oli veira. pdf>. Acesso em 01 abr 2012.

PESAVENTO, Sandra Jatahy. História \& história cultural. 2. ed. Belo Horizonte: Autêntica, 2008.

PRADO, Maria Lígia Coelho. Desafios do historiador brasileiro face às utopias latino-americanas do século $\quad \mathbf{X X}$ Disponível em: <http://www.snh2011.anpuh.org/arquivo/download?ID_ARQUIVO=24378.>. Acesso em 13 fev. 2012.

SCHMIDT, Mário Furley. Nova História Crítica: ensino médio. vol. único. $1^{\mathrm{a}}$ ed. São Paulo: Nova Geração, 2005.

SILVA, Vitória Rodrigues. O ensino de História da América no Brasil. Disponível em: $<$ http://www.uem.br/dialogos/index. php?journal=ojs\&page =article\&op=viewArticle \&path\%5B\%5D=180> . Acesso em 04 mar. 2012.

SCHMIDT, Maria Auxiliadora; BARCA, Isabel; MARTINS, Estevão de Rezende (Orgs.). Jörn Rüsen e o ensino de história. Curitiba: UFPR, 2010. 
RÜSEN, Jörn. Razão histórica: teoria da história: fundamentos da ciência histórica. Brasília, DF: UnB, 2001.

História viva. Brasília, DF: UnB, 2010.

. Narrativa histórica: fundamentos, tipos, razão. In: SCHMIDT, Maria Auxiliadora; BARCA, Isabel; MARTINS, Estevão de Rezende (Orgs.). Jörn Rüsen e o ensino de história. Curitiba: UFPR, 2010b. p. 93-108.

SILVA, Tomaz Tadeu. A produção social da identidade e da diferença. In: SILVA, Tomaz Tadeu (Org.). Identidade e diferença: a perspectiva dos estudos culturais. 10. ed. Rio de Janeiro: Vozes, 2011b. p. 73-102.

VICENTINO, Cláudio; DORIGO, Gianpaolo. História Geral e do Brasil. vol. 1. São Paulo: Scipione, 2010.

VICENTINO, Cláudio; DORIGO, Gianpaolo. História Geral e do Brasil. vol. 2. São Paulo: Scipione, 2010.

VICENTINO, Cláudio; DORIGO, Gianpaolo. História Geral e do Brasil. vol. 3. São Paulo: Scipione, 2010.

WOODWARD, Kathryn. Identidade e diferença: uma introdução teórica e conceitual. In: SILVA, Tomaz Tadeu (Org.). Identidade e diferença: a perspectiva dos estudos culturais. 10. ed. Rio de Janeiro: Vozes, 2011. p. 7-72. 